\title{
Intensity High at 1995 MRS Spring Meeting
}

A hush fell across the halls of the San Francisco Marriott April 17-21 as over 2,500 attendees of the 1995 MRS Spring Meeting huddled in meeting rooms intently listening to presentations on a wide assortment of materials research topics. In addition to orchestrating symposia on materials properties, processing, and fundamentals, Meeting Chairs Marcia H. Grabow (AT\&T Bell Laboratories), George M. Pharr (Rice University), and Jeffrey Y. Tsao (Sandia National Laboratories) worked to develop applications-oriented symposia that cut across a range of materials. For example, the visible light-emitting materials and devices symposium covered nitrides, II-VI compounds, and organic materials. Symposia covered flat panel display materials, magnetic and optical materials, energy storage, superconductors, modeling, biomaterials, materials for sports and recreation, and a wide assortment of other topics in a total of 26 symposia plus Frontiers of Materials Research, Symposium X.

\section{Plenary Presentation and Tissue Engineering}

No longer is it enough for artificial bone and tissue replacements to cause no harm to the body while restoring lost function, now biomaterial developments aim to aid restoration of function and development of the body's own parts, such as through drug delivery based on controlled release and organ regeneration by building living tissue on degradable structures. Plenary speaker Robert Langer, the Kenneth J. Germeshausen Professor of Chemical and Biomedical Engineering at MIT, illustrated his 21 years of research and progress in synthesizing new polymers and biomaterials for drug delivery and tissue regeneration. He detailed the questions his research team asked and the experiments devised to help find resolutions. Langer has studied

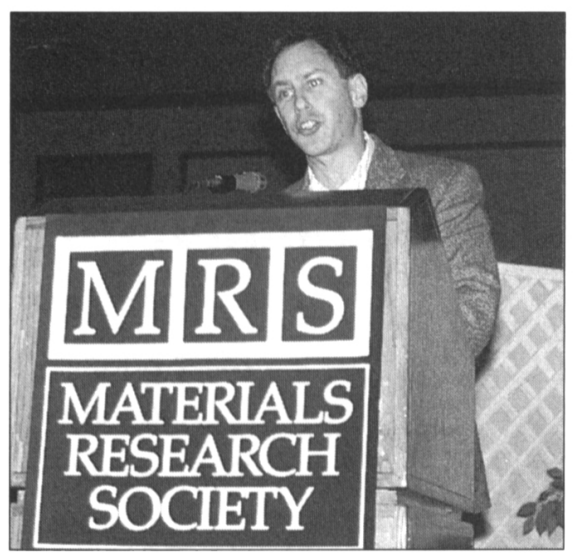

Robert Langer, the Kenneth J. Germeshausen Professor of Chemical and Biomedical Engineering at MIT, gives the plenary presentation, "Biomaterials: New Polymers and Novel Applications." the possibilities of developing polymers to slowly release drugs into the body. With the onset of genetic engineering and biotechnology in the late 1970s and 1980s, the problem of releasing drugs of large molecular weight became more urgent, accelerating Langer's research. One of the highlights of his successes is the development of a biodegradable polymer disk that can be placed in the brain rather than the bloodstream of a patient suffering from brain cancer. In this way, the drug is released at the site of the tumor, avoiding previous side effects that damaged the liver, kidney, and spleen.

Langer addressed research that revolutionized materials used for medical applications. In treating organ failure, rather than limit physicians to the use of materials from the commercial sector, such as sausage casing for dialysis tubing, Dacron clothing for vascular grafts, or mattress stuffing for breast implants, research in tissue engineering has led to materials synthesized specifically to treat medical problems. See Langer's edited transcript, "Biomaterials: New Polymers and Novel Applications," elsewhere in this issue.

The plenary presentation set the pace for a three-day symposium on polymers in medicine and pharmacy (Symposium $Z$ ), including a talk by W. Mark Saltzman (Johns Hopkins University) on polymers for tissue engineering, which was presented jointly with Symposium $X$ as a review for nonspecialists. Saltzman discussed organ regeneration through the process of culturing cells onto polymer scaffolds. Once cells proliferate to regenerate the lost organ, the polymer scaffold can be designed to biodegrade. He discussed how cell behavior on synthetic polymer surfaces depends on the surface

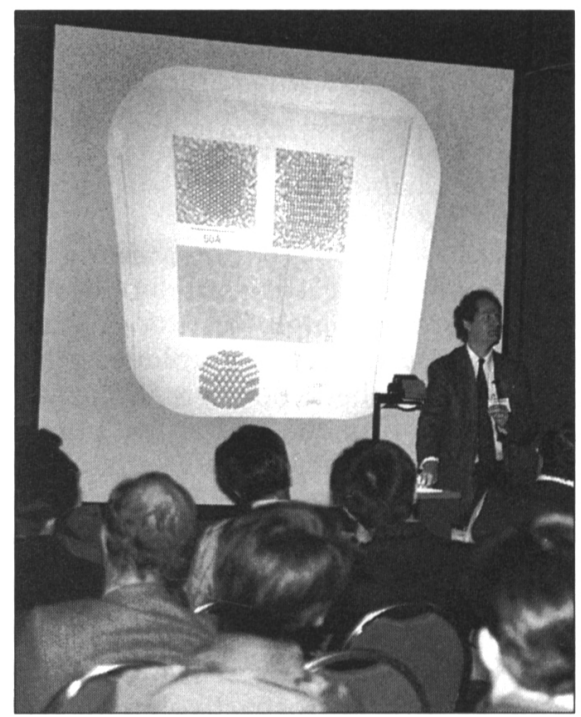

\section{A. Paul Alivisatos, recipient of the Outstanding Young Investigator Award, describes his work on nanostructures.}

chemistry. For example, cell-cell interaction can be influenced by water-soluble, hybrid polymers; and cell adhesion peptides immobilized to poly(ethylene glycol) promote neural cell adhesion.

\section{Awards}

Maybe one day it will be possible to make functioning electronic materials in a beaker of liquid, but for now the excitement of nanocrystals resides in the research lab, revealing interesting phenomena and extending the dimensions of knowledge, while shrinking physical dimensions. A. Paul Alivisatos, from the University of California at Berkeley, received the 1995 Outstanding Young Investigator Award, which was presented to him by John Bravman, immediate past president of MRS, during the Plenary Awards Ceremony. In a special lecture during the technical sessions, Alivisatos described some of the marvels of nanostructures. Now that it is possible to form nanocrystals, the next challenge will be to study the properties of the tiny surfaces, to control those surfaces, to study defects they contain, and-eventually - to attach electrical leads to the crystals, Alivisatos said. His presentation can be found elsewhere in this issue. 
Also at the Plenary Presentation, MRS Treasurer A. Kay Hays announced the 12 recipients of the Graduate Student Award (see photo). The award recognizes graduate students whose academic achievements and current materials research display a high order of excellence and distinction. Each recipient receives a $\$ 250$ cash prize, payment of the registration fee for the meeting, and a presentation plaque. The awards were based on abstracts accepted at the Spring Meeting and a 10-minute talk during a special student presentation at the meeting.

\section{Money in the Bank and Bank Notes Rely on Materials Research}

A noontime forum focused on "Entrepreneurship: Materials for Money." It addressed what is needed to start a company based on materials research and it revealed what some MRS entrepreneurs are doing and how MRS can assist them (see sidebar). One speaker offered his experiences developing technology relating to flat-panel displays, while another described a private venture capital partnership with a focus on advanced materials and specialty chemicals.

While materials research can lead to good money in a business sense, it also can be used to prevent the proliferation of bad money, in the form of counterfeit currency. Sandra L. Hyland from the National Research Council presented a lunchtime talk in Symposium X, Frontiers of Materials Research, authoritative reviews for nonspecialists, "Making Money (i.e. Dollar Bills) Using Materials Science," which described ways to modify the inks and substrates of currency to hinder counterfeiting.

Members of the audience set aside their boxed lunches and held dollar bills up to the light, examining the polyester security thread listing the denomination of the bill, an attribute only visible in transmission. This feature was introduced into U.S. currency in denominations of $\$ 5$ and up starting with the 1990 series, along with the addition of microprinting around the portrait that says United States of America written too small to be reproduced with current photocopying processes.

Charged with investigating alternatives for a major redesign of U.S. currency to deter counterfeiting, materials scientists have considered several features to combat the improved copying capabilities counterfeiters now enjoy in sophisticated scanners and color photocopiers. A totally new design (the first since the 1920s) is

\section{Graduate Student Award Finalists}

At the 1995 MRS Spring Meeting, 12 graduate students were honored, whose academic achievements and current materials research displayed a high order of excellence and distinction. Pictured are:

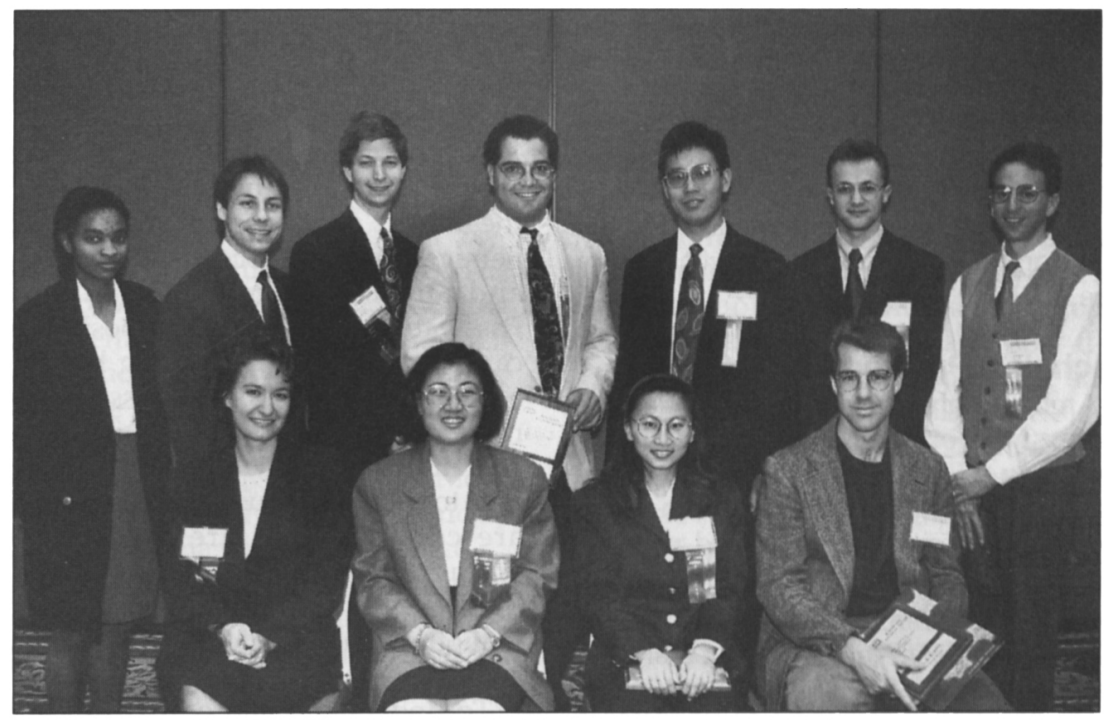

(seated left to right) Eden Zielinski (Stanford University), who presented paper T14.4: "The Influence of Strain Energy Minimization on Abnormal Grain Growth in Copper Thin Films"; Chuhee Kwon (University of Maryland), paper K2.9: "The Effect of Adjacent Layers on the Superconducting Properties of Uitrathin $\mathrm{ReBa}_{2} \mathrm{Cu}_{3} \mathrm{O}_{7}$ Films"; Yi-Chia Chen (University of California--Irvine), paper S3.12: "In-Cu Multilayer Composite Solder for Fluxless Bonding"; and Brett A. Kraabel (University of California-Santa Barbara), paper H7.4: "Subpicosecond Photoinduced Electron Transfer from Conjugated Polymers to $C_{60}$ with Long-Lived Charge Separation"; (standing left to right)Yvette V. Baxter (Caltech), paper M2.8: "The Effect of Brownian Motion on the Behavior of Electrorheological Fluids"; Ray D. Twesten (University of Illinois at Urbana-Champaign), paper C6.4: "Direct Measurement of Stress at Surfaces and Interfaces at the Microscopic Level"; Mark Visokay (Stanford University), paper L5.8: "Growth and Characterization of [001] and [111] Oriented Intermetallic Compound Thin Films"; John Lombardi (University of Arizona), paper J3. 10: "Hard Coatings for PET Films Using Si(NCO) ${ }_{4}$ Sol-Gel Precursors"; Haike K. Dong (University of California-San Diego), paper Q18.2: "Effects of Laser Irradiation on Growth and Doping Characteristics of GaAs in Chemical Beam Epitaxy"; Guenole C.M. Sivestre (Trinity College), paper B2.3: "Nucleation and Growth of Defects in SOI Materials"; and Lee E. Rumaner (University of Washington), paper G3.2: "Substrate Effects on the Nucleation and Growth of GaSe Layers by Van Der Waals Epitaxy." Silke Christiansen (Universität Erlangen-Nürnberg), paper C8.18: "How do

Dislocations Influence the Strain Distribution in an Undulated Epitaxial Layer-A

Three-Dimensional Finite Element Approach," is not pictured.

The other finalists (not pictured) were Nora Virginia Edwards (North Carolina State University), Vinay K. Gupta (Caltech), Adelina llie (Ecole Polytechnique), Donald Y.C. Lie (Caltech), Joanna Mirecki-Millunchich (Northwestern University), Masanori Otobe (Tokyo Institute of Technology), Yongjo Park (Carnegie-Mellon University), Philip Rack (University of Florida), Rahul Sharangpani (Clemson University), and Yonghong Yang (University of Illinois at Urbana-Champaign). All of the students presented papers at the various symposia.

due to begin release in 1996, starting with higher denominations. The new bill will have a different look with features that play with the reflection, transmission, refraction, and diffraction of light, such as iridescent microprinted planchets, a watermark of the portrait, machinedetectable threads and fibers, intaglio microprinting, and color-shifting ink made from thin films with different refractive indices.

While researchers have found strategies to deter counterfeiting and increase durability, they have yet to design bills clearly distinguishable by denomination for the 3.9 million users who are visually impaired. Hyland said that the simplest solution would be to change the size of 
bank notes per denomination-which has societal challenges of getting U.S. citizens to adapt, rather than materials research challenges.

\section{Electronic Publishing Initiatives}

Twelve publishers displayed their electronic publishing products for meeting attendees to try out as a service of the MRS Publications Committee Task Force on Electronic Publishing. Five representatives later convened as panelists for the Electronic Publishing Initiatives Forum (see sidebar).

\section{Technical Program}

Among highlights in the technical program, superconductivity regained visibility. Steve Foltyn from Los Alamos National Laboratories described an incremental but exciting step toward producing flexible tapes and wires of ceramic superconductors-a necessary prerequisite for widespread use of the high-temperature superconductors. Using ionbeam-assisted deposition to produce a textured intermediary layer of YSZ, Foltyn and his group produced a YBCO superconducting film on a flexible polycrystalline $\mathrm{Ni}$ substrate. The research achieved the milestone of $100 \mathrm{~A}$ on a big piece and $1 \mathrm{MA} / \mathrm{cm}^{2}$ at $77 \mathrm{~K}$ in a 1 micron-thick piece of superconductor, and being able to bend the material around a 1-in.-diameter cylinder while retaining $90 \%$ of $J_{C}$ at $1 \%$ compressive strain.

The increasing worldwide interest in portable power sources was reflected in a new MRS symposium, Symposium W, Materials for Electrochemical Energy Storage and Conversion-Batteries, Capacitors and Fuel Cells. The development of high performance power sources for applications ranging from portable electronics to electric and hybrid vehicles is intimately linked with availability of advanced materials. Several talks described the government initiative, a Partnership for a New Generation Vehicle, and how the needs of this program are dependent on advanced materials. The initiative has a goal of an $80 \mathrm{mpg}$ car. Lightweight materials, advanced power generation, high-efficiency bearings, and other types of materials are needed for this initiative. Nickel metal hydride and lithium ion batteries received the most attention as these rechargeable electrochemical systems have the highest projected energy and power densities.

In Symposium Y, Materials for Environmental Protection-The Control of Air Quality, issues of automotive catalysts (how to reduce auto emissions) were discussed as well as removal of oxides of nitrogen and chlorinated hydrocarbons from flue gases by using other catalytic methods. Stable oxide membranes can be used for conversion of methane to synthesis gas, which has the benefit of using an available resource.

Beyond clean air, materials researchers seek to clean semiconductors, which was the subject of Symposium O, Ultraclean Semiconductor Processing Technology and Surface Chemical Cleaning and Passivation. This year's symposium indicated that gas-phase cleaning has finally emerged as a serious process option. A new emerging problem is organic contamination, which is a difficult problem to tackle because the contaminants are complex, and are not abundant enough to study easily. As scanning probe techniques grow in use, contamination on the atomic scale will grow as an issue.

To understand and address the problem of materials reliability, quantitative modeling has become an important focus. In Symposium T, Materials Reliability in Microelectronics $V$, modeling ranged from reliability simulation for entire circuits through modeling of microstructure development in metallization, to prediction of the effects of different microstructures on stress development and failure.

Technology roadmaps were a recurring theme during the meeting, particularly in Symposium S, Electronic Packaging Materials Science VIII. It emphasized materials research, development, and processing issues identified in the National Technology Roadmap. Also, a panel of experts from industry and academia covered a variety of topics including the ever increasing need to emphasize cost issues and to define an evolutionary path from the relatively high cost approaches of today to the low cost systems of the future.

As an integral part of Defect and Impurity Engineered Semiconductors and Devices (Symposium B) and Symposium X, Frontiers of Materials Research, Hans J. Queisser from the MaxPlanck-Institut für Festkörperforschung reviewed the science base for siliconsemiconductors. Queisser's talk on "Order and Disorder in Semiconductors" outlined the evolution of the "Silicon Age." He expounded on the uniqueness of semiconductors in requiring a highly purified and spatially homogeneous material to start with, and then profoundly altering the electrical and optical prop- erties with subsequent microscopic disordering by trace dopants. And beyond history, he addressed defect analysis, simulation, in situ control, and contactless measurements.

Building on its strong base, the microelectronics industry is pushing critical feature sizes in electronic circuits to ever smaller dimensions. However, the point at which scaling becomes no longer possible is fast approaching. Indeed, it appears that a paradigm shift in both fabrication technology and device physics will be needed at the beginning of the next century. Key to such technical issues are the materials issues associated with structures on the $50 \mathrm{~nm}$-size-scale. The status and prospects for existing technologies for patterning and electronic devices were reviewed in Symposium D, Materials Fabrication and Patterning at the Nanoscale, targeting at what dimensions scaling will no longer be possible. Proximal x-ray lithography is being developed as an alternative technology for manufacturing, while another attractive approach is based on proximal probes. For example, C.F. Quate of Stanford University showed the results of lithography using the atomic force microscope (AFM) for making submicron structures and devices. Working devices are now made using the AFM, and line widths of $70 \mathrm{~nm}$ and smaller $(20 \mathrm{~nm}$ amorphous hydrogenated silicon lines) have been demonstrated.

Not only in electronics are small dimensions sought. Data storage capacity grows by shrinking feature sizes on magnetic and optical media. The quiet explosion of ultrahigh density data storage was evident in Symposium L, Magnetic Ultrathin Films, Multilayers and Surfaces, as well as in Symposium X. Ultrahigh density magnetic data storage has experienced a 500,000-fold increase in area density since magnetic recording was first introduced in 1957, and is further expected to increase. Toward that end, $15 \mathrm{~nm}$ nickel pillars have already been fabricated demonstrating the principle of a 65 Gbit/in ${ }^{2}$ magnetic disk. In a related Symposium $X$ presentation directed toward the technical nonspecialist, John Simonds, who was director of the National Storage Industry Consortium, described how the consortium has been used to enhance U.S. competitiveness in the storage industry through joint precompetitive research. The consortium, with over 80 member organizations including universities, government laboratories, and companies, has five-year technology targets to develop magnetic 
disks with a storage capability of 10 Gbits/in ${ }^{2}$, magnetic tapes with a storage capability of 1 terabyte/in ${ }^{3}$, and optical disks that can store $10 \mathrm{Gbits} / \mathrm{in}^{2}$.

Light emission in a rainbow of colors was discussed in Symposium E, Visible Light Emitting Materials and Devices. Polymeric, molecular, and inorganic (compound semiconductor) light emitters were compared and contrasted, including $\mathrm{GaN}$ which has been cast as a potential short wavelength light (blue and blue/green) emitter. Also reported were the relative merits of various II-VI and III$\mathrm{V}$ materials for blue-green diode lasers, explaining that $\mathrm{CdZnSe}$ has promise for use in CD players, leading to an extended playing time over that given by the current AlGaAs diode laser, if microscopic defects can be controlled.

In Flat Panel Display Materials, Symposium $V$, presenters reported on active-matrix liquid crystal, field emission, electroluminescent (EL), and color plasma displays, covering liquid crystals, glass substrates, amorphous silicon, and polycrystalline silicon. Thin-film EL displays need improvement of blue phosphors for display applications, although S. Sun (Planar America, Inc.) showed a sample of a full color 5-in. TFEL display. One presentation considered the hope of producing a curved flat panel display that can be wrapped around a person (immersive cockpit concept). While amorphous $S i$ active matrix LCDs are the state of the art, there is a drive toward using single- or polycrystalline silicon. In addition to flat panel displays, amorphous silicon technology is advancing for applications in solar cells, sensors, and photovoltaic/electrochromic window coatings, yet a scientific understanding is far from complete. For example, the creation of metastable defects by illumination and recombination currents are not yet understood, although the effect was discovered in 1977.

A panel discussion was held on "Issues and Challenges in Manufacturing with Energetic-Beam-Growth Processes" in Symposium Q, Film Synthesis and Growth Using Energetic Beams. The purpose of the panel was to assess promise of various techniques for use in manufacturing. Panelist Jim Greer (Raytheon) presented issues and challenges of manufacturing using pulsed laser deposition. Obstacles include a lack of basic infrastructure, the need for higher deposition rates, and the problem of particulates. Off-axis PLD, which has the plume parallel to the wafer so the particles go whizzing by, can be used to reduce the particulate problem. However, an amorphous or porous structure forms, thereby losing the benefit of PLD. Syd Wilson (Motorola) described how the drive toward higher speed and lower operating voltage (leading to lower power operation) is moving silicon-on-insulator technology (SOI) forward. Reduced power consumption means lighter batteries for laptops. The buried oxide is generally formed by implanting high doses of oxygen at high temperatures $\left(\sim 1350^{\circ} \mathrm{C}\right)$. The primary problems are variable and low beam current, low throughput, and high defects, although dislocations and other defects were found to be less of a detriment to electrical properties than first thought. Other panelists discussed ionized sputtering, and a new technique using an RF plasma reactive ion source.

In the area of multilayers, one investigator reported metal/polymer multilayers grown to micron-scale thicknesses on substrates moving in excess of $120 \mathrm{~m} / \mathrm{s}$. The most prominent emerging applications for multilayered materials appeared to be as hard coatings and structural elements. Several authors showed an increase in apparent hardness at bilayer periods between 2 and $10 \mathrm{~nm}$, as measured by conventional nanoindenter techniques.

Hard coatings ranging from automotive glazing to resilient flooring and magnetic media were the subject of Symposium J, Hard Coatings for Plastic
Substrates Materials, Processes and Properties. In general, coatings needed to be thicker than 1-4 $\mu \mathrm{m}$ to adequately improve tribological properties, although carbon-based coatings produced by ion implantation and related techniques gave improvements for films less than $500 \mathrm{~nm}$, provided ion bombardment doses were sufficient.

Bicycles, skis, and baseball bats are filled with materials innovation. In Symposium AA, Materials in Sports and Recreational Activities, researchers described both the materials developments in sports equipment and how the developments can be used to inspire students to learn about materials processing, engineering analysis, and design. A panel discussion involved four manufacturers of bicycle components: Craig Calfee from Carbonframe, Gary Helfrich from Arctos, Chris Hinshaw from Beyond, and Ric Hjertberg from Wheelsmith. Topics covered included the use of materials such as beryllium, high modulus graphite fiber, titanium, and stainless steel.

Other technical topics included strained layer epitaxy, fullerenes, diamond, rapid thermal and integrated processing, modeling and simulation of thinfilm processing, electromechanical phenomena in complex fluids, low-dielectric constant materials, and thin films for integrated optics applications. For more information on specific symposia, see the summaries on the following pages and the MRS Symposium Proceedings.

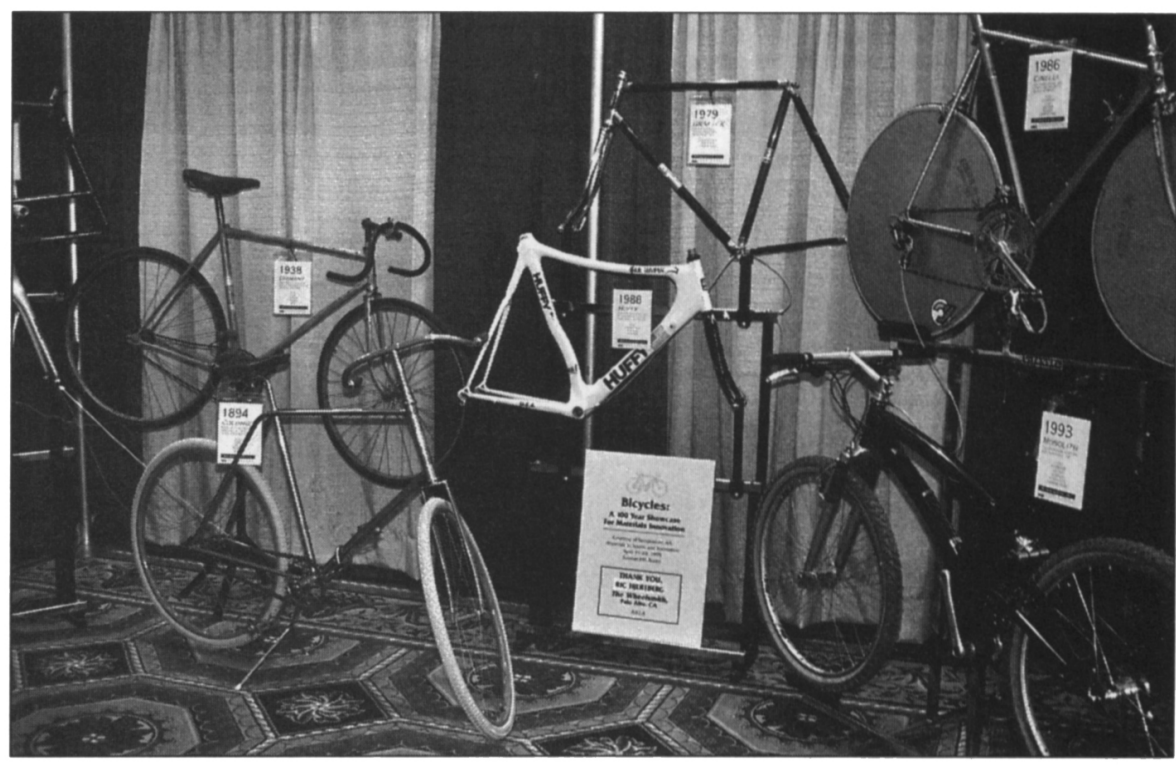

Symposium AA, Materials in Sports and Recreational Activities, exhibits a bicycle display to show 100 years of materials innovation. 


\section{Publishers Display and Discuss Electronic Products and Services}

During the 1995 Spring Meeting, MRS hosted a special publishers' display and forum on electronic publishing. The two-day event enabled scientists to see first-hand the many types of electronic journals, indexing systems, and "electronic libraries" offered by the front-running publishers of electronic products and services. It also enabled scientists a direct view into the business of electronic publishing-what opportunities and obstacles professional societies and commercial publishers are facing as they move rapidly to convert scientific information from paper to electronic formats.

Twelve publishers displays were open Monday evening and Tuesday morning during the Spring Meeting where meeting attendees browsed, tested, and discussed features of the products with publisher representatives. Participants in the displays were American Astronomical Society, Academic Press, American Chemical Society, American Institute of Physics, ASM International, Beacon Graphics, Elsevier Science, IBM T.J. Watson Center, IEEE, Lightbinders, Optical Society of America, and MRS. For a complete description of products displayed and contact information, see the MRS homepage, http://www.mrs.org/, under

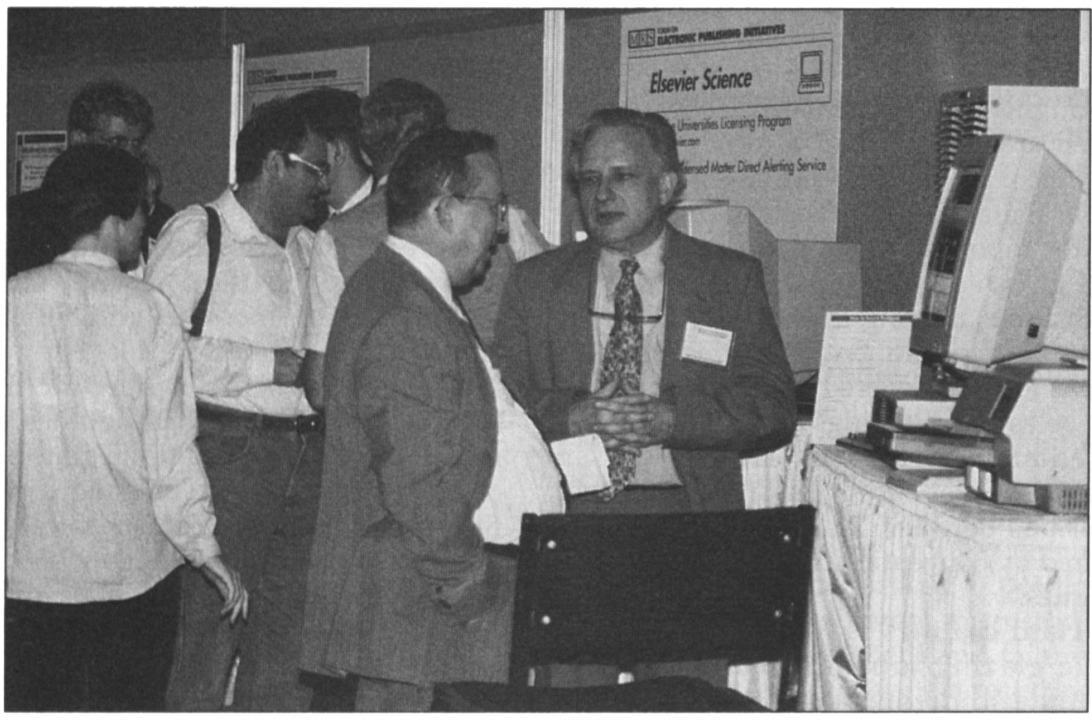

Meeting attendees look over the range of electronic publishing possibilities.

"What's New." The Tuesday evening forum hosted five presentations reporting the results of various electronic publishing experiences and future directions planned by the publishers. Speakers included Tim Ingoldsby (AIP), Peter Shepherd (Elsevier Science), Lorrin Garson (American Chemical Society), Peter Boyce (American Astronomical Society), and Peter Goldie (Lightbinders).

Both scientists and publishers benefited from the forum. Because both the form and function of electronic journals are still evolving, the forum offered meeting attendees a groundfloor opportunity to articulate their concerns regarding formats, electronic standards, cost, and copyright issues which the publishers eagerly welcomed in order to chart a course for delivering effective electronic products and services in the future. (This issue of MRS Bulletin also reports the results of a survey of the Spring Meeting attendees, covering these and other electronic publishing issues.) The Electronic Publishing Initiatives display and forum was presented as a service by the MRS Publications Committee Task Force on Electronic Publishing, chaired by John Baglin. A comprehensive report, including technical details and discussion of strategic implications for MRS, is available from John Baglin, phone (408) 927-2280, e-mail baglin@almaden.ibm.com.

\section{New Concepts and Controversy Surround a-Si-Based Materials}

(See MRS Proceedings Volume 377)

Symposium A, Amorphous Silicon Technology-1995 is the thirteenth in an annual series which commenced in 1983. This year's symposium included many reports on devices incorporating amor- phous silicon (a-Si) as well as on the continuing efforts to understand the structure and properties of the broad range of a-Si-based materials. The device reports range from new concepts such as photovoltaic/electrochromic window coatings to current products such as active matrix liquid crystal displays (AMLCD) and solar cells. The middle ground between these two extremes in device maturity is amorphous silicon sensors. Sensor arrays based on a-Si pin diodes are in an advanced state of development at Xerox as reported by R.A. Street and his colleagues. These arrays will be used both for monochromatic applications such as $x$-ray imaging as well as for color scanning. Several papers described the direct use of a-Si pin diodes for three-color sensing.

These advances in a-Si devices are still made with an incomplete scientific understanding of a-Si-based materials. For example, no consensus understanding has emerged for the Staebler-Wronski effect (the creation of metastable defects by illumination and recombination currents), which was discovered in 1977. Several papers discussed the recent proposal of slow defect relaxation by J.D. Cohen and his colleagues at the Univ. of Oregon stating that the atomic relaxation which follows the change in charge state of a defect requires seconds to finish in a-Si, as opposed to the picoseconds required in crystals. This view is controversial, and the interpretation of a crucial capacitance experiment in terms of defect relaxation was challenged by W.B. Jackson and N.M. Johnson of Xerox, who find that similar effects can be due to slow carrier injection by a c-Si/a-Si contact interface.

Symposium Support: Sanyo, Fuji, MitsuiToatsu Chemicals, Xerox, Energy Conversion Devices, EPRI, United Solar Systems, Voltaix, ISI-PV, Sharp.

\section{Queisser Gives “Pioneer's Perspective" on Semiconductors (See MRS Proceedings Volume 378)}

This follow-up of a highly successful 1992 MRS symposium again brought together researchers with many perspectives on defects in semiconductors. Intended principally to encourage creative applications of defects and impurities, Symposium B, Defect-and ImpurityEngineered Semiconductors and Devices, continued to exert widespread interest with nearly 240 presentations.

An early pioneer's perspective on "Order and Disorder in Semiconductors" was given in the keynote talk by H.J. Queisser of the Max Planck Institute. He expounded on the uniqueness of semiconductors in requiring a highly purified and spatially homogeneous material to start with, and then profoundly altering the electrical and optical properties with subsequent microscopic disordering by trace quantities of "impurities" (The 


\section{Entrepreneurs Get Down to Business}

Inspired by her own entrepreneurial interests, Marcia Grabow from AT\&T Bell Laboratories and co-chair of the 1995 MRS Spring Meeting coordinated a lunchtime forum entitled, "Entrepreneurship: Materials for Money." The goals were twofold: first, to present speakers who have addressed what is needed to start a company, and who could explain what capital investors are looking for in a business; and second, to identify what entrepreneurs who are members of MRS are doing and how MRS can assist them.

Robert Pressley, president of Silicon Video Corporation, offered tips based on his experiences of why and how to go into a materials business. Silicon Video Corp. is developing displays using proprietary field emission cathodes for electron emission to achieve CRT-like performance in a flat-panel display. One of Pressley's key points in his talk was for entrepreneurs to not fund the business themselves, but to use a personal contact for their first financing group and, when they are ready, to approach a venture firm.

The accompanying speaker, Thomas R. Baruch, is a general partner of Chemicals and Materials Enterprise Associates (CMEA), a private venture capital partnership with a focus on advanced materials and specialty chemicals. Baruch explained his experiences on venture formation and venture capital investments. He provided perspectives on the venture capital industry in general and pointed out other sources of capital.

During the session, Joe Catalano from Excellim Corporation was introduced as the conlact person for the MRS Entrepreneur Initiative (EI). His first task is to install an active presence for entrepreneurs within the MRS homepage on the World Wide Web to serve as an active locus for the interaction of entrepreneurs within MRS, and also as a link to the larger world outside. It will, for example, help entrepreneurs locate potential partners, and sources of capital or marketing expertise.

Catalano said that entrepreneurship has an interesting place within the normal scope of MRS activities. While materials-specific topics create the breadth of MRS meetings, entrepre neurial topics cut across all of the materials disciplines. Entrepreneurs are involved in every field of materials science and engineering, and, by design or necessity, some MRS members are starting materials businesses, which makes MRS the ideal venue for entrepreneurs in the materials field to interact. For suggestions, comments, or to get involved, contact Joe Calalano, phone (201) 455-1214, fax (201) 455-0845, or e-mail xtalkid@ aol.com.

Dopant Doctrine). Apart from giving a historical perspective of defects in silicon, he summarized recent advances in defect analysis, theory of simulation and in situ control and contactless measurements. He noted the emergence of devices with reduced dimensions and the possibility of memory devices based on multiatomic bistable configurations using perhaps hydrogen in Si.

Symposium Support: MEMC Electronic Materials, Photowatt Int'l., Shin-Etsu Handotai, RIBER, Xerox, Hughes, Toyota, Nippondenso, NEC, Sumitomo Electric Industries, Balzers, Wacker Chemitronic, Fujitsu, Matsushita, JOBIN-YVON, Kodak.

\section{Epitaxy Research Strains to Reveal Effect of Carbon on Bandgap of GeSiC}

(See MRS Proceedings Volume 379)

Symposium C, Strained Layer Epitaxy-Materials, Processing, and Device Applications, delivered the intended conference environment: a mix among materials researchers producing new materials and processes for device applications. Both column IV and III-V materials were highlighted in the symposium.

In particular, current trends in $\mathrm{GeSi}$ materials and devices were highlighted by D. Monroe of AT\&T and H. Presting of Daimler-Benz (DB). The AT\&T work has carried the use of GeSi in CMOS concentration than previous heterojunction bipolar transistors (HBTs), DB was able to dope the base with a very high dopant concentration, achieving a maximum frequency $f_{\max }$ of $90 \mathrm{GHz}$.

On the materials front, mosaic spread in relaxed GeSi structures was investigated with reciprocal space maps using $\mathrm{x}$-ray diffraction, showing that this is a useful technique for probing these complex structures. Other material issues addressed included 2D-wavy-3D growth morphologies, and the parameters and understanding that dictate the surface morphology and buried strained layers of strained GeSi. The sign of the mismatch strain was shown to be an important factor influencing the formation of nonplanar surfaces.

$\mathrm{GeSiC}$ was an extensively reported area of research at this meeting. Researchers argued about the effect of adding $C$ on the bandgap of the ternary and binary $\left(C_{x} S_{1-x}\right)$, but a consensus was forming that linearly interpolating between pure semiconductors and the alloys is crude and incorrect; in fact, addition of $C$ appears to shrink the bandgap.

Relaxation in the III-V materials was also extensively reported, involving two issues: the understanding of the initial relaxation and its dependence on substrate miscut, and the growth and properties of relaxed graded mismatched layers.

A review of phase separation in III-V materials by $K$. Hsieh of the Univ. of Illinois showed the progress that has been made in understanding the complex nature of the microscopic phase separation that occurs. Characterization of strained InGaAs/GaAs quantum wells was reported for a variety of techniques, By using a square well with greater Ge

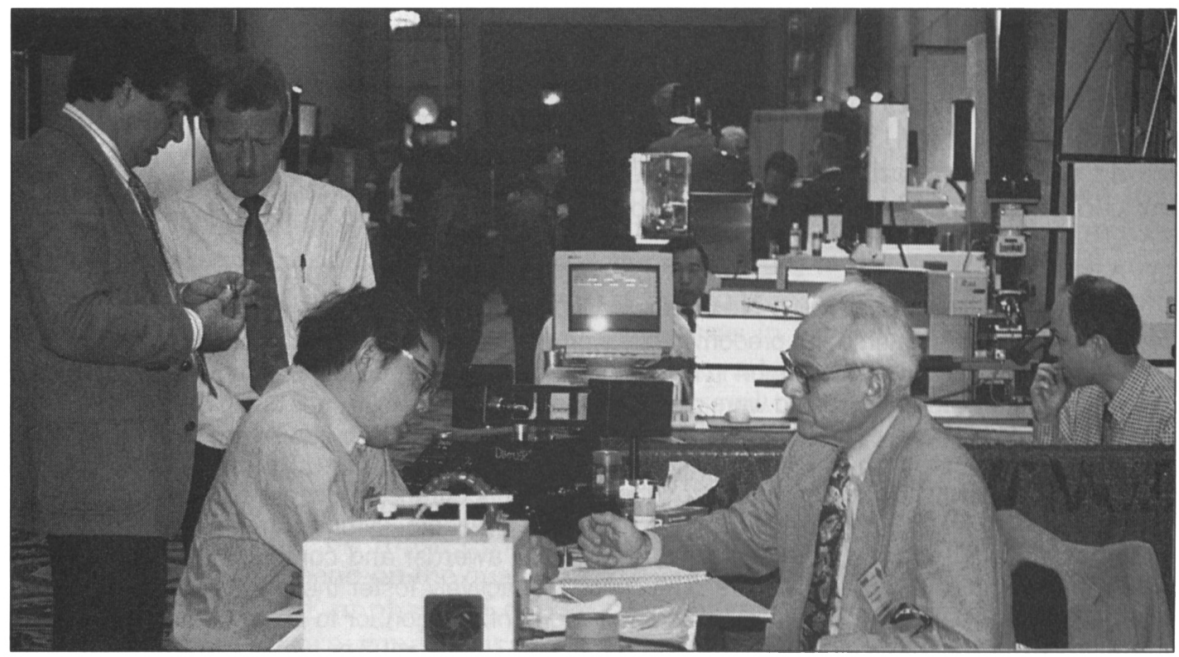

Meeting attendees gather information at the exhibitors' booths. 
and $\mathrm{J}$. Coleman of the Univ. of Illinois showed how InGaAs active layers in lasers can improve the laser reliability. Multiple strained layers both on relaxed and lattice-matched material were reported for the fabrication of optical modulators.

An interesting combination of talks on the forefront of materials fabrication for device applications was reported. Many of the issues regarding the new materials and structures are not resolved and should be interesting areas of research in the future.

Symposium Support: American Xtal Technology, EMCORE, Lawrence Semiconductor Research, Instruments SA, Philips, Morton Int'l., Applied Materials.

\section{Microelectronics Industry Shrinks Critical Dimensions to Nanoscale (See MRS Proceedings Volume 380)}

Symposium D, Materials-Fabrication and Patterning at the Nanoscale, focused on materials issues associated with the fabrication and manufacturing of structures and devices with critical dimensions below $100 \mathrm{~nm}$. The microelectronics industry, which projects the production of circuits with critical dimensions of 100 $\mathrm{nm}$ within 15 years, provides the main motivation.

Extensions of CMOS technology are projected to function at $30-\mathrm{nm}$ gate lengths. Materials issues include silicides for sub-100-nm dimensions, low parasitic interconnects, and high-quality thin $(\sim 3$ $\mathrm{nm}$ ) gate oxides. Nanometer scale dimensions for magnetic storage has a similar need. For example, arrays of 15-nm nickel pillars have been fabricated demonstrating the principle of a $55 \mathrm{Gbits} / \mathrm{in}^{2}$ magnetic disk

Optical lithography has always been the workhorse for the microelectronics industry. As dimensions have shrunk, tremendous increases in functional density (rather than speed) have been achieved along with a dramatic drop in cost per function. However, we may no longer be able to maintain these trends as we approach critical dimensions of $150 \mathrm{~nm}$. We need technology capable of being engineered for feature sizes down to $\sim 50$ $\mathrm{nm}$. Proximity $x$-ray appears to fit this description although it has many economic- and materials-related issues to overcome. An increasingly attractive approach is based on proximal probes, addressed in a series of papers. Proximal probes can be used for material manipulation at the molecular and atomic scale and could be developed into a technology capable of manufacturing production. The use of self-assembling materials and hydrogenated silicon for ultrathin imaging layers, along with the direct modification of silicon, titanium, and siloxane surfaces, may be promising approaches for proximal-probe-based lithography.

\section{Integration of Low Dielectric Constant Materials Captures \\ Discussion \\ (See MRS Proceedings Vol. 381)}

The majority of the papers in Symposium F, Low Dielectric Constant Materials-Synthesis and Applications in Microelectronics, aimed at materials and integration issues related to the next generation on-chip interconnect applications. Synthesis, characterization, and process integration of low dielectric constant polymer materials dominated the theme. In addition to the fluorinated and nanofoam polyimides, novel low dielectric constant materials that can be either vapor deposited or photocurable were reported. Strategies to lower the dielectric constant of the conventional $\mathrm{SiO}_{2}$ films including porous oxides and the fluorination of $\mathrm{SiO}_{2}$ were also reported. Several metal/polymer integration schemes were reported, one of which used both $\mathrm{SiO}_{2}$ and low dielectric constant polymer where polymer was only used in between very narrow metal gaps to reduce the cross-talk.

Symposium Support: Advanced Micro Devices, SEMATECH, TI, IBM, Motorola, Allied Signal.

\section{MRS Members Discuss Needs of Women in Materials Science}

Forty-five MRS members, predominantly women, congregated for an early morning meeting to discuss the needs of women in materials science. Numerous ideas on how to best serve and promote women in the field were discussed and several are currently being pursued.

An e-mail list has been set up for the group, and volunteers are now being sought to create a bulletin board on the MRS homepage that would include links to other networks of women scientists. The group recognized the need to encourage the involvement of women in all aspects of MRS. This includes serving as invited speakers, symposium organizers, meeting chairs, and officers; being nominated for MRS awards; and contributing to the MRS Bulletin as authors or guest editors. The group will actively foster these activities and meet again during the 1995 MRS Fall Meeting. For more information, or to be placed on the electronic list, contact MRS Membership Services: 412-367-3004 x402 or e-mail info@ mrs.org.

\section{Hardness Coatings Emerge as Leading Application for Multilayered Thin Films (See MRS Proceedings Vol. 382)}

Symposium G, Structure and Properties of Multilayered Thin Films, covered recent developments and emerging applications in multilayered materials. Improved techniques for characterizing structural properties of multilayers were presented, including the in situ observation of dislocation formation and fracture of multilayers using transmission electron microscopy, and the use of optical techniques to measure monolayer-bymonolayer changes in stress in multilayers as they are formed.

Several novel and high-speed deposition processes were introduced, including vapor jet deposition and ion implantation to achieve multilayer structures. One investigator reported metal/polymer multilayers grown to micron-scale thicknesses on substrates moving in excess of $120 \mathrm{~m} / \mathrm{s}$. Materials issues in multilayers for x-ray optics were also heavily discussed. While immiscible materials in a multilayer are less sensitive to phase formation, they also can agglomerate at elevated temperatures. Some interesting cases of metastable phase formation in immiscible layered systems, for instance, cobalt-carbon, were also presented. The most prominent emerging applications for multilayered materials appear to be as hardness coatings and structural elements. Several authors showed an increase in apparent hardness at bilayer periods between 20 and $100 \AA$ as measured by conventional nanoindenter techniques. T. Barbee (LLNL) showed largearea, millimeter-thick sheets formed at bilayer periods of several nanometers. Symposium Support: Pure Tech, Nano Instruments, MDC Vacuum, Enraf-Nonius, Surface/Interface, Siemens, Charles Evans \& Assoc.

\section{Hard Coating Improves Capabilities of Plastic Substrates}

Symposium J on Hard Coating For Plastic Substrates-Materials, Processes, and Properties highlighted the broad range of material systems in which "hard coating" a plastic substrate provided dramatic improvement in performance relative to an uncoated plastic. The need for hard coatings appeared universal, with diverse application areas including automotive glazing and molded parts, solar reflectors, aircraft windows, resilient flooring, and magnetic media. Specific and dramatic improvements in performance were described for abrasion and 
scratch resistance, adhesion, water and oxygen permeability, uv-blocking and optical performance, and friction. In general, the coatings needed to be thicker than 1-4 $\mu \mathrm{m}$. Exceptions were high quality "carbon-based" coatings produced by ion implantation and related techniques. These promising materials improved performance with relatively "thin" $(<5,000 \AA)$ coatings. Thick, hard coatings made from $\mathrm{SiO}_{2}, \mathrm{Al}_{2} \mathrm{O}_{3}$, and fluropolymer-doped $\mathrm{Al}_{2} \mathrm{O}_{3}$ required ion bombardment during synthesis. In all cases, the level of bombardment was critical in determining the coating properties and/or the coating deposition rate. Processes included plasma-enhanced chemical vapor deposition (PECVD), ionassisted physical vapor deposition (IAPVD), and ion-beam-assisted deposition (IBAD). All of the vacuum processes seemed adequate for low volume production, especially when thinner coatings $(<1 \mu \mathrm{m})$, high margin products were prepared. However, for products which require high production volumes and thick ( $>1-4 \mu \mathrm{m}$ ) coatings, new or improved (high-rate) process tools had to be developed. For those products, materials such as specialty polymers formulated with silica/silicones were available and are currently in widespread use. The future may see interesting developments in the use of sol-gel impregnation techniques and biomimetics.

Symposium Support: Chemat.

\section{High- $T_{C}$ Superconductors Moved Closer to Practical Use}

High-Temperature SuperconductorsMaterial and Fabrication Issues for Applications, Symposium K, focused on the material and fabrication aspects of high-temperature superconductors (HTS). Interest in the topics has developed with the realization that applications of the superconductors will be limited by the complex materials processing and fabrication steps. The symposium was divided into thin-film related sessions and bulk materials.

J. Rowell (Conductus, Inc.) showed that tremendous progress had been made in thin film depositions and thin film related devices in a relatively short time for the oxide materials. Many issues, especially cheap and compatible substrates, still remain to be resolved. K.E. Myers described DuPont's effort to in situ fabricate $\mathrm{Tl} / \mathrm{Pb}$ based superconducting thin films and multilayers. T.J. Marks (Northwestern Univ.) showed progress made in MOCVD deposition of various oxide thin films including the supercon-

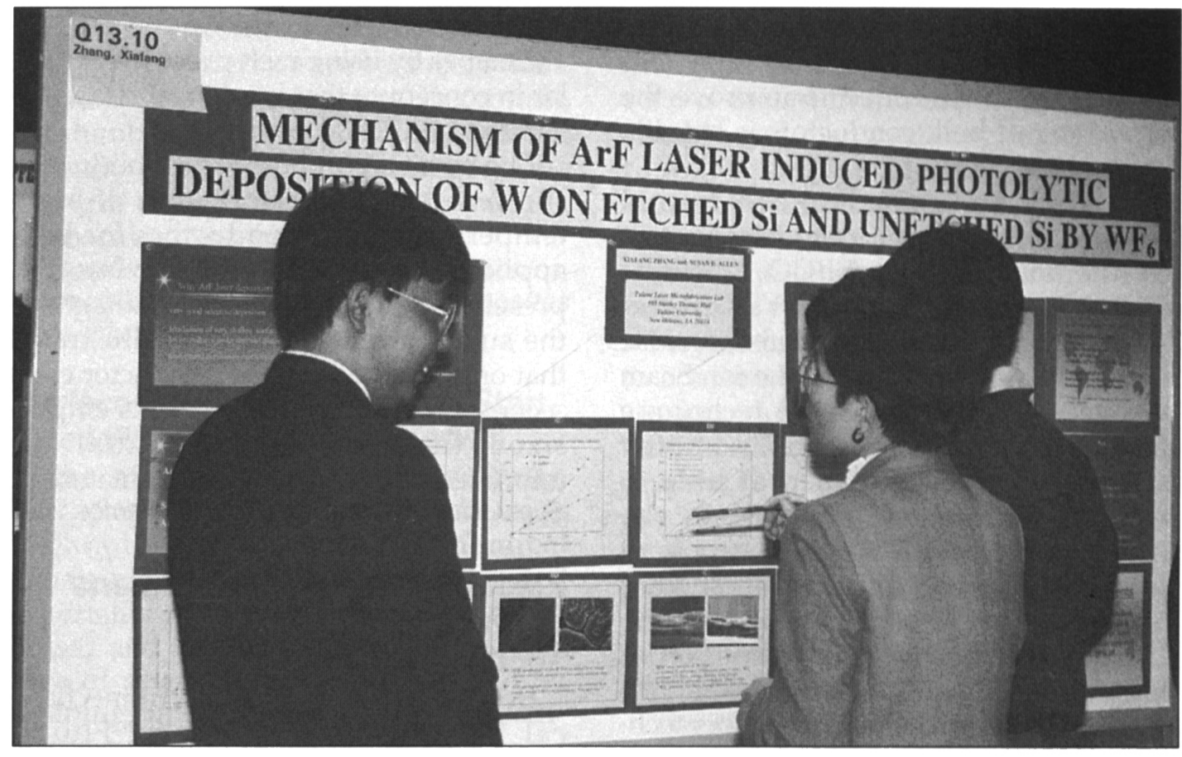

Researchers discuss their work at the poster sessions.

ductors, and precursor development needed for precise control of the composition of the films. S. Oda (Tokyo Institute of Technology) demonstrated that substrate surface defects result in film outgrowth/smoothness and showed how to obtain extremely smooth YBCO thin films. In the following session on HTS thin films and multilayers, J.M. Phillips (AT\&T) reviewed the materials issues affecting applications of high $\mathrm{T}_{c}$ thin films.

K.S. Harshavardhan (Neocera, Inc.) discussed pulsed laser deposition of high quality superconducting thin films on technologically important substrates such as yttrium iron garnet. I. Bozovic (Varian Research Center) showed the great control of atomic layer epitaxial possible for growth of superconducting multilayers and devices. During the session on HTS junctions and SQUIDs, J.Z. Sun (IBM) showed processing controls on fabrication of step edge grain boundary weak links and SQUIDs while J. Clarke (UCBerkeley) clearly demonstrated that noise in HTS SQUIDs had been reduced by many orders of magnitude in the last few years by improving the materials and processing steps.

During the session on microwave devices and interfaces, D. Oates (Lincoln Labs.) showed experimental evidence that the realization of high power microwave devices depend on the quality of HTS thin films, and emphasized that further material improvements were needed. K. Setsune (Matsushita) indicat- ed that good microwave device design reduces the need of further materials improvements.

J.W. Ekin (NIST) presented electrical measurements on the various interfaces to understand the nature of interfaces. Clearly, further improving materials and finding the correlation between microstructure and superconducting properties will be the key for potential application of the superconducting thin films related devices.

The talks and posters associated with bulk and wire applications of high-temperature superconductors furthered the increasingly broad understanding of these complex materials. They also provided new technological approaches to fabricate high performance conductors. The presentations reflected that $\mathrm{BSCCO}$ based wires are being built with higher critical current density and longer length; the performance of $\mathrm{Bi}-2223$ conductors is approaching that necessary stage for commercial application. Specific applications included fault current limiters, current leads, and magnets. The sources of AC losses in composite superconductors and ways to mitigate these losses were addressed. Talks on current limiting mechanisms focused on the importance of locally variable critical current density, percolative paths, and cracks in the oxide superconductors. Presentations on the dependence of critical current on strain emphasized the important role of cracks in limiting supercurrent flow. Knowledge about the phase equilibria and 
microstructural evolution in the multicomponent high-temperature superconducting systems needed to improve the processing of bulk conductors is steadily improving.

Folytn from Los Alamos National Laboratory presented significant new results on thick film YBCO-123 films deposited on an oriented YSZ buffer layer on a flexible metallic substrate. $\mathrm{He}$ reported that by modifying the ion beam assisted deposition (IBAD) technique used to deposit the aligned YSZ buffer layer, his research team was able to achieve $1 \mathrm{MA} / \mathrm{cm}^{2}$ at $77 \mathrm{~K}$ in the 1-micron-thick YBCO-123 film deposited on the YSZ by laser ablation. These films retained a significant portion of their critical current when strained in tension or compression, retaining greater than $90 \%$ of $J_{c}$ at $1 \%$ compressive strain. This technique should be scaleable to fabricate long length conductors.

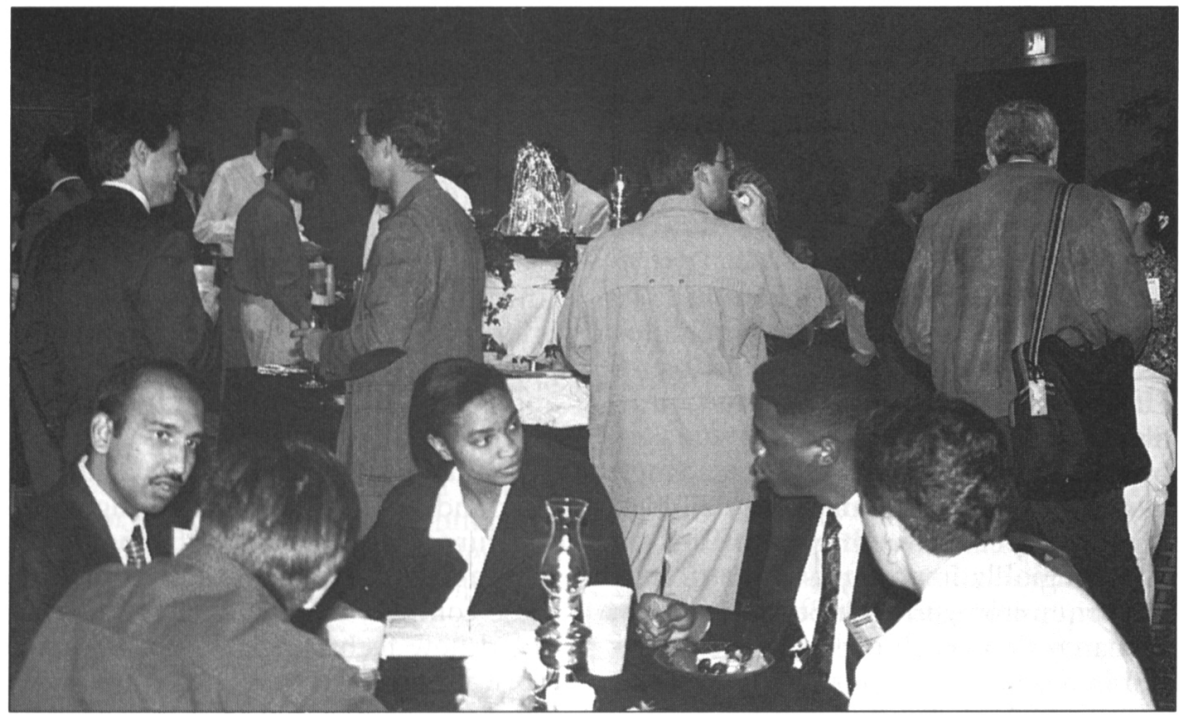

Students enjoy an informal gathering at the Graduate Student Mixer.

A. Pashitski at the Univ. of Wisconsin presented magnetooptic images of the transport current paths in BSCCO tapes. These clearly showed the current is concentrated in a region near the Ag interface and does not flow in the center of the tape.

Y. Shiohara of ISTEC discussed models for growth rates in different directions in YBCO-123. He also showed the Czochralski technique that researchers now use to grow single crystals of YBCO-123.

V. Selvamanickam of Intermagnetics General reported that researchers had

achieved some texture in Ag-sheathed Tl1223 tapes by using melt processing, similar in concept to that used to fabricate Agsheathed Bi-2212 conductors.

The sessions on bulk superconductors showed that the performance of hightemperature superconductors for bulk applications is steadily improving. The presentation of magnetooptic images of the supercurrent graphically illustrated that only a fraction of the conductor cross section carries supercurrent. This emphasized the enormous potential for improved performance in these materials. Symposium Support: ORNL, Los Alamos.

\section{Electromechanical Phenomena in Complex Fluids Fill Technological Need}

Symposium $M$ was on Electromechanical Phenomena in Complex Fluids, including electrorheological (ER) fluids, magnetorheological (MR) fluids, magnetic fluids (MF), and electromechanical gels 
areas of applications where interfaces and their properties play a significant role such as with biointerfaces, microelectronics, polymer composites, and interpenetrating polymer networks (Symposium N, Polymer/Inorganic Interfaces).

Tailoring surface properties of substrates, and hence interfaces, involves the use of both self-assembled monolayers and tethered copolymers (brushes) for controlling surface energy, lubricity, biocompatibility, adhesion, and topography. Polymeric brushes have the ability to modify their morphology as the solvent parameter or $\mathrm{pH}$ changes. The use of primers influences adhesion of polymers to metals either by altering the chemical interactions forming reactive species that hasten chemical bonding or altering acidbase interactions, or by altering the mechanical performance such as tensile strength and viscoelastic properties of that primer coating.

Characterization techniques allow for the further understanding of properties at interfaces. For example, ellipsometric characterization of ultrathin polymeric films yields data on the swelling of these films on exposure to solvents. The direct measurement of polymeric and interfacial energies allows for further understanding of adhesion and surface science of polymeric coatings. The use of transmission electron microscopy (TEM) and differential scanning calorimetry (DSC) enable the study of the fiber/matrix interfacial morphology and may-contribute toward understanding the properties of composite interfaces. X-ray photoelectron spectroscopy (XPS) measures the bond formation between metal-carbon as well as metal-oxygen-carbon interaction that yields the chemical characteristics of metal/polymer interfaces and may assist in optimization of their adhesion. Furthermore, near-edge $x$-ray absorption fine structure (NEXAFS) elucidates the orientation of bonds at buried polymer/metal interfaces. This nondestructive analysis allows for the measurement of interfacial chemical interactions between the polymer and metal, and may be useful in optimizing adhesion in these types of systems.

Many chemical, morphological, and physical factors control performance of interfacial adhesion and durability. For urethane/glass interfaces, the phase separation and preferential deposition of one phase of the resin strongly influences adhesion. Measuring the presence of water at coating/substrate interfaces can be useful in monitoring and understanding the durability of that coating. For car- bon fiber composites, the durability of the fiber/matrix interface appears to be dominated by mechanical factors. In contrast, the durability in glass fiber composites is strongly dependent on maintaining the strength of both the glass fiber and the interface on exposure to water.

Symposium Support: Physical Electronics, Surface/Interface, Automotive Composites Consortium.

\section{Surfaces Make an Ultraclean Start (See MRS Proceedings Volume 386)}

The attendance at Symposium $\mathrm{O}$, Ultraclean Semiconductor Processing Technology and Surface Chemical Cleaning and Passivation, exceeded expectations and is testimony for the continued and increased significance of this area of science and technology. Wafer cleaning, microcontamination, and surface passivation remained the key focus of the symposium. The symposium included related technologies, such as chemo-mechanical polishing (CMP) and the associated cleaning steps, which outlined future opportunities and challenges in this field.

The session on aqueous wafer cleaning focused on control of surface morphology, as well as particle and molecular contamination removal. It was dominated by work aimed at improving the standard RCA SC-1 cleaning step, mainly through the use of elaborated design-ofexperiments. Reduced-chemical-consumption cleaning is clearly feasible without sacrificing cleaning efficiency. Such cleans have already been implemented by several semiconductor manufacturers. The session on aqueous wafer cleaning also emphasized TCAD modeling efforts to optimize equipment flow pattern and thus, e.g., rinsing efficiency to reduce process time and cost. Surprisingly, the effects of megasonics, in manufacturing use for several years, are not well-understood. Significantly more effort is needed to elucidate the effects of megasonics on boundary layer diffusion, cavitation, and streaming potentials.

CMP was reviewed as an emerging technology to which this community can contribute significantly. While CMP has been in manufacturing use both at wafer suppliers and microelectronics manufacturers for many years, the field offers substantial opportunity for research as well as innovation, e.g., in the area of slurry development. Our understanding of the mechanisms of CMP, as well as postCMP cleaning, i.e., particle adhesion and its dependence on $\mathrm{pH}$ and surfactant use, was seen to be rudimentary at best.
Gas-phase cleaning seems to emerge finally as a serious process option. The state-of-the-art in this area is progressing steadily and manufacturing implementation at a larger scale can be expected around the 1 Gbit generation.

A session on process integration highlighted the level of sophistication that present-day manufacturing, e.g., of the 64 Mbit generation, has to take into account to achieve acceptable yield levels. This session particularly put in context the field of wafer surface preparation with respect to preceding and subsequent process steps and the associated process interactions. It also highlighted the multiple options for process trade-offs. Issues of cluster integration and device characterization that will become critical in future technologies were considered.

The emphasis on acceptable microcontamination lf.vels and techniques to characterize these ever-decreasing levels highlighted the emergence of organic contamination as a serious microcontamination issue. Mostly due to the complexity and scarcity of the contaminants this presents a tremendous challenge to this community. Another focus area is the application of scanning probe techniques in situ to enhance our understanding of cleaning processes while they occur at an atomic level.

Symposium Support: SubMicron Systems, Legacy Systems, Balzers, Santa Clara Plastics, Solid State Equipment, CFM Technologies, ONTRACK Systems, Sony, Hitachi, Fujikin, Toshiba, Mitsubishi, TI, Fujitsu, Matsushita, NEC, Sharp, Nomura Micro Science.

\section{RTP Gains Status in Manufacturing Process}

(See MRS Proceedings Vol. 387)

Manufacturing-related aspects of rapid thermal processing (RTP) technology regarding equipment maturity, process repeatability, throughput, and cost of ownership was the focus of Symposium $P$, Rapid Thermal and Integrated Processing IV. K. Reid (Motorola) and R. Thakur (Micron Technology) described the manufacturing-floor level problems associated with the insertion of RTP for high-volume production applications. Motorola presented additional data to compare the economical as well as technical benefits of RTP over conventional batch furnace processing.

Knowing the inherent difficulty with widespread acceptance of RTP technology is related to lack of adequate temperature measurement control capability, the organizers clarified the understanding of 
the present status of temperature measurement methodologies and control strategies. J.P. Hebb's (MIT) work on the effects of multilayer patterns and $\mathrm{H}$. Xu's (Princeton Univ.) studies on surface roughness effects were major presentations.

Another focus area was the status and implementation strategies of simulation and modeling for the concurrent engineering concept of equipment manufacturing, including work on physical-model based simulation for CVD, concurrent design of the RTP reactor, and artificial neural network. RTP technology is finally making some headway and being regarded as a reliable semiconductor manufacturing tool.

Symposium Support: AG Assoc., AST Elektronik, SubMicron Systems, CVC Products.

\section{Beam Synthesis Possibilities Escalate \\ (See MRS Proceedings Vol. 388)}

As research in energetic beam synthesis of thin films becomes ever more diverse, progress is clearly being made in understanding fundamental processes, and prospects for new materials and device technologies reliant on beam synthesis are coming into focus that did not exist even five years ago. Symposium Q, Film Synthesis and Growth Using Energetic Beams, brought together theoreticians and experimenters working on film growth and modification with energetic beams, with significant discussion of progress in pulsed laser deposition, ionbeam-assisted deposition, ion implantation, and supersonic jet growth.

Prominent aspects of the symposium included a panel discussion on "Issues and Challenges in Manufacturing with Energetic-Beam-Growth Processes," which surveyed the commercial promise of pulsed laser deposition, silicon on insulator prepared by separation and isolation by implantation of oxygen or SIMOX, highly ionized beam sputtering for via filling in advanced microelectronic interconnects, and reactive atom beam sources for growth of wide-gap nitride and II-VI semiconductor devices.

The extremely lively and well-attended session on synthesis of nitrides covered growth issues for $\mathrm{TiN}, \mathrm{GaN}$, and $\mathrm{C}_{3} \mathrm{~N}_{4}$. Progress on understanding clustersurface interactions was also reported with detailed experimental work and molecular dynamics simulations providing new insights.

Symposium Support: Martin Marietta, Lumonics, High Voltage, Hauzer Techno Coating European BV, Lambda Physik, Spectra-Physics Lasers.

\section{National Technology Roadmap Guides Discussion of Electronic Packaging \\ (See MRS Proceedings Vol. 390)}

Symposium S, Electronic Packaging Materials Science VIII, emphasized materials research, development, and processing issues identified in the National Technology Roadmap. A number of invited speakers described various aspects of the roadmap and relevant industry and government-funded programs.

Using flip chips on organic substrates as a case study, C.A. Steidel, recently retired from Intel, described how high performance/low cost packaging solutions for future products require a sound understanding of the relations between basic material properties and package performance, manufacturability, reliability, and quality. In the case of flip chip, short-term needs include the development of low-temperature reflowable solders with good fatigue resistance, optimization of the underfill process and materials, and the optimization of board materials and construction in terms of low cost and high chip density.

The materials research community at universities and national laboratories should, however, be encouraged to emphasize the development of the necessary models, systematic evaluation methods, and metrology tools, leaving the actual application to the users. R.R. Tummala (Georgia Tech) described an ambitious program in which their Packaging Research Center plans to raise the number of electronic packaging courses offered from the current 25 to about 50 within five years.

P. Totta (IBM) had organized a panel discussion with experts from industry and academia covering a variety of questions, including the ever-increasing need to address cost issues and the need to define an evolutionary path from the relatively high cost approaches of today to the low-cost systems of the future.

Symposium Support: Intel, SEMATECH, Universal.

\section{Materials Reliability in Microelectronics Quantitatively Modeled}

(See MRS Proceedings Vol. 391)

Greater miniaturization and complexity of design ensure that materials reliability remains a key concern for the microelectronics industry. The well-attended sessions of Symposium T, Materials Reliability in Microelectronics V, illustrate that this regular symposium is now the major forum on the materials science of device reliability and failure.

Much experimental work was reported, particularly in situ studies of electromigration in scanning and transmission electron microscopes, and it remains crucial for identifying fundamental mechanisms. A highlight of the symposium was the presentation of high-quality work on quantitative modeling, ranging from reliability simulation for entire circuits, through modeling of microstructure development in metallization, to prediction of the effects of different microstructures on stress development and failure. Techniques such as these should greatly facilitate the development of reliable circuits.

To resolve severe problems with existing materials, the development of copper as the basis for interconnect metallization was reported. It would replace aluminum which suffers extensively from electromigration damage.

Stresses are known to be significant in many thin films, and microelectronic circuits can show mechanical failure due to these stresses. The highlights of work reported on strains and stresses include high spatial resolution of stress measurements and direct determination of interfacial fracture energy in multilayer structures. The links between stress and electromigration and voiding in interconnects were explored.

Progress was also reported in hotcarrier-induced degradation in MOSFET devices, and degradation and breakdown of dielectrics, contacts, and barrier layers. Electrical measurements were shown to be sensitive in characterizing device degradation.

Symposium Support: Sandia, Nat'l. Semiconductor, Motorola, AT\&T, SEMATECH, Digital Equipment, MRC, Tencor Instruments, IBM, Advanced Micro Devices.

\section{Thin Films Integrate into Optical Applications \\ (See MRS Proceeding Vol. 392)}

Symposium U, Thin Films for Integrated Optics Applications, reported on issues in the development of Thin Films for Integrated Optics Applications. Sessions centered on the nonlinear optical applications of organic crystals; two aspects of ferroelectric liquid crystal (FLCs), including FLCs on VLSI and the potential of FLC for nonlinear optical (NLO) applications; and inorganic thin films.

That the field is quickly progressing is exemplified by the achievement of large electrooptic coefficients ranging from 45 to $55 \mathrm{pm} / \mathrm{V}$, measured at $1.3 \mu \mathrm{m}$ (where 
lithium niobate has an electrooptic coefficient of $31 \mathrm{pm} / \mathrm{V}$ ), and by systems with chromophores covalently attached to polymers with long-term $(>1,000 \mathrm{~h})$ stability at temperatures of $100^{\circ} \mathrm{C}$. R.J. Twieg (IBM) pointed out that chromophores now exist that can be poled at temperatures in excess of $400^{\circ} \mathrm{C}$.

Two aspects of ferroelectric liquid crystal (FLC) for integrated optics were addressed including FLCs on VLSI, and the potential of FLC for (NLO) applications. Regarding the former, T.J. Drabik (Georgia Tech) and M.D. Wand (Displaytech) described an optical chip comprised of an FLC thin film integrated with a custom silicon VLSI circuit. The device is an electrooptic modulator with $256 \times 256$ elements with $65 \mathrm{~K}$ channels running in parallel at $10 \mathrm{kHz}$ in an active area approximately $5 \times 5 \mathrm{~mm}$.

R.U. Petscheck (Case Western Reserve Univ.) discussed work aimed at creation of a chiral ferroelectric smectic A materials. The jury is still out regarding the question of whether such phases have been found. Undoubtedly, chiral smectic $C$ materials (FLCs) are polar and thus of some interest for second order NLO applications. S. Sprunt (NRL) showed that in at least one system, thin film crystals can be grown directly from the FLC phase, with some degree of control over crystal morphology, by application of AC electric fields. The crystals grown in this way exhibited a large second harmonic generation signal relative to the FLC phase from which they grew. K.E. Arnett (Displaytech) presented his work on measurement of the $r$ coefficient in an FLC material designed for enhanced second order susceptibility and reported the fastest electrooptic measurement on an FLC material to date $\left(r_{22}=3,1.4=\mathrm{pm} / \mathrm{V}\right.$ for $633 \mathrm{~nm}$ light modulated at $200 \mathrm{MHz}$ ).

In the area of inorganic thin films, R.R. Neurgaonkar reviewed the recent developments in ferroelectric thin films for electrooptic and NLO applications. He indicated that Rockwell has been developing thin films of PZT (lead zirconium titanate), PBN (lead barium niobate), and PSKNN (a solid solution between lead potassium niobate and strontium potassium niobate). These systems have linear electrooptic coefficients $r_{33}$ greater than that of $\mathrm{LiNbO}_{3}$ or poled polymers, with values estimated to be $500-600 \mathrm{pm} / \mathrm{V}$. D.K. Fork (Xerox) addressed some of the key issues in obtaining low-loss ferroelectric thin films, indicating that surface roughness of the thin films remains a major impediment to obtaining low-loss materials. Nevertheless ferroelectric films with losses of the order of $1 \mathrm{~dB} / \mathrm{cm}$ have been reported. Of special note was the development of an integrated erbiumdoped glass optical amplifier with a gain of $19 \mathrm{~dB}$ or $4.2 \mathrm{~dB} / \mathrm{cm}$.

\section{Improved Phosphors Needed for Emissive Displays to Compete with AMLCD Flat Panel Displays}

Flat Panel Display Materials, Symposium V, covered active-matrix liquid crystal displays (AMLCD), field emission displays (FED), electroluminescent displays (EL), and color plasma displays (CPD), among others. A joint session with Symposium A (Amorphous Silicon Technology) included some general comments on AMLCDs and overviewed some of the important material concerns including the liquid crystal and the glass substrate. D. Hopper (Wright Patterson AFB), discussed the potential of FPDs in government and military-related applications, not only AMLCDs with improved efficiency and reduced costs, but also emissive displays. In addition, he discussed the various government-sponsored research programs.

The focus of the TFT session was primarily on poly-Si technology, particularly laser recrystallization and other postannealing effects.

Two sessions focused primarily on emissive displays, particularly EL displays and FEDs. S. Sun (Planar America) reviewed thin film EL displays and the need for improvement of blue phosphors for display applications. He showed a sample of a full-color 5-inch TFEL display. In terms of FEDs, it appears that with the evolution of more efficient phosphors and a focus on low voltage processes, they will be more competitive with AMLCD in the future.

In the session on plasma displays and luminescent materials, an overview of color plasma display technology was presented by S. Mikoshiba (Univ. of ElectroCommunications in Tokyo). In addition, the Phosphor Technology Center of Excellence, headquartered at Georgia Institute of Technology, received much attention. It is involved in the study of phosphor for EL, FED, and CPD. Several presentations introduced potential phosphor materials.

Symposium Support: Corning, ARPA, DOE.

\section{Portable Power Sources Spark Research in Electrochemical Energy Storage and Conversion (See MRS Proceedings Vol. 393)}

The increasing worldwide interest in portable power sources was reflected in a new symposium (W), Materials for Electrochemical Energy Storage and Conversion-Batteries, Capacitors, and Fuel Cells. The development of high performance power sources for applications ranging from portable electronics to electric and hybrid vehicles is intimately linked with availability of advanced materials.

The session began with keynote presentations from the U.S. Depts. of Commerce and Energy that outlined the structure, motivation, and future materials needs for the Partnership for a New Generation of Vehicles. The goal of this joint government/automotive industry endeavor is to develop a hybrid vehicle that has low emissions and is energy efficient (>80 mpg) by 2005 while retaining performance of current midsized sedans. In addition to the use of fuel cells, batteries and/or capacitors, these vehicles will require mass and aerodynamic drag reduction, recovery of energy on braking, and improved driveline efficiencies, all of which will require new and improved materials.

The most demanding need for fuel cells is improved electrolytes. While catalyst loadings have decreased dramatically over the last few years, high conductivity electrolytes need to be developed to carry the high current density needed for hybrid vehicle applications. Inorganic (silicates and aluminates) as well as organic polymer systems-modified poly(ethylene oxide)-were discussed. Batteries require improved electrolytes as well as anode and cathode materials. Nickel metal hydride and lithium ion batteries received the most attention as these rechargeable electrochemical systems have the highest projected energy and power densities. For example, high capacity lithium intercalation carbons (exceeding $\mathrm{LiC}_{6}$ ) obtained by silicon doping were discussed by A. Wilson (Simon Fraser Univ., Canada). A. Nagai (Kureha Chemical Industry Co., Japan) used NMR evidence to propose a "lithium cluster model" to explain the high capacity of nongraphitizable carbons. Carbon (and ruthenium oxide) electrodes are also being developed as electrodes for electrochemical capacitors.

\section{Polymers Stretch Across Biomaterial Spectrum (See MRS Proceedings Vol. 394)}

Symposium Z, Polymers in Medicine and Pharmacy, was divided into thematic sessions on orthopedic applications, polymers for drug delivery, polymers for tissue engineering, biointeractions and 
biointerfaces, properties and characterization of polymers, and synthesis and processing of polymers, presenting many advances, both fundamental and application-oriented.

R. Langer's group at MIT presented a series of papers dealing with the application of degradable polymers for tissue regeneration. Fabricating poly(glycolic acid) into fibrous mesh, they examined the behavior of tenocytes, periosteal cells, and chondrocytes cultured on these scaffolds in vitro and in vivo. When developed successfully, these implants would be useful for regeneration of tendon, bone, and cartilage.

M. Yaszemski (Wilford Hall Medical Center) introduced the development of a degradable composite material based on a linear polyester of propylene glycol and fumaric acid. This unsaturated polyester is polymerizable at the time of surgery. In vivo histologic studies in rats show progressive material degradation with time and bone replacement of the degraded material. R. Siegel (UC-San Francisco) presented a theoretical model of designing

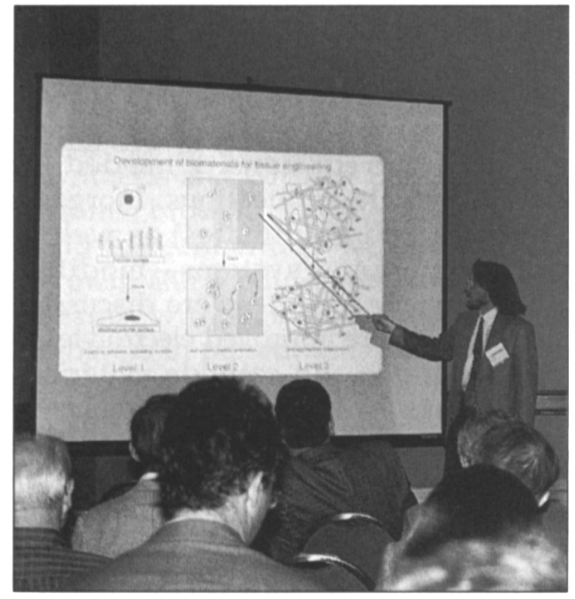

W. Mark Saltzman from Johns Hopkins University illustrates cell behavior on synthetic polymer surfaces in his discussion of organ regeneration.

a gel-membrane-based drug delivery oscillator. Based on the swelling and deswelling of a hydrogen membrane, the delivery oscillator can be realized with the coupling of the substrate and product mass transfer with the enzyme reaction rate. J. Cleland (Genentech) discussed the commercial development of PLGA microsphere formulations that provide either a continuous or pulsatile release of intact native proteins for vaccine applications.

Symposium Support: Genentech, ATRIX, Syntex, Cygnus Therapeutic Systems, Smith \& Nephew Research.

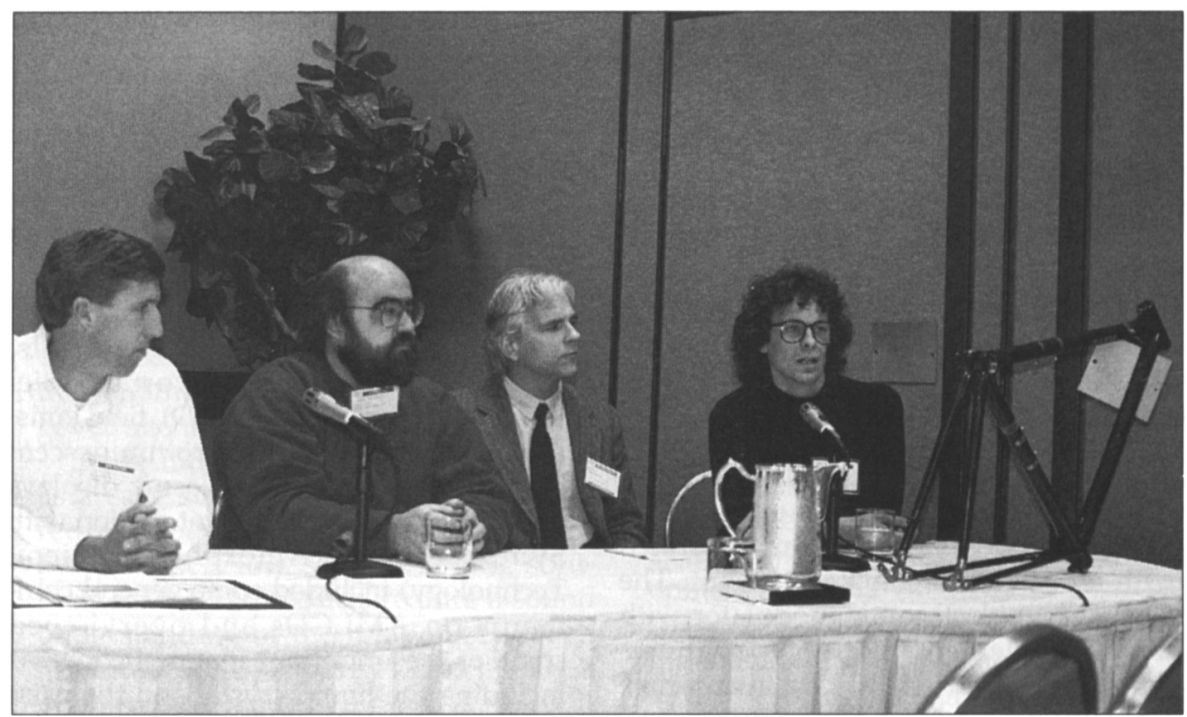

In a panel discussion, manufacturers of bicycle components (from left to right) Chris Hinshaw from Beyond, Craig Calfee from Carbonframe, Ric Hjertberg from Wheelsmith, and Gary Helfrich from Arctos covered topics such as the use of materials ranging from beryllium to high modulus graphite fiber to titanium to stainless steels.

\section{Materials in Sports Hits Homerun}

M.F. Rudy, consultant for NIKE and inventor of the NIKE-Air ${ }^{\circledR}$ System and the Head-Air Ski Boot, kicked off Symposium AA on Materials in Sports and Recreational Activities. He reviewed all aspects of his invention from the initial idea, followed by development of the idea into a tangible object, to finally marketing the product. According to Rudy, successful marketing of an invention is far more difficult than devising and developing the invention. He surprised the audience by showing that the first patent for an air-cushioned sole for a shoe appeared in about 1880, and that nearly a century passed before his technical developments and perseverance in marketing of the invention yielded a commercially successful product.

The symposium held more surprises as the audience learned how large the worldwide market and advanced the design technology is for windsurfing, and that sports equipment, because of its strong demand on performance and lesser sensitivity to cost, is a fertile market to initially commercialize the use of advanced glass fiber and metal matrix composite systems.

Three professors in Departments of Materials Science and Engineering demonstrated how their analysis of sports equipment as a basis in courses covering engineering materials and design kindled students' enthusiasm for learning about materials processing, engineering analysis, and design.

G. Michal presented design equations that were used to predict the effects of changing the design and materials used for a baseball bat on how far a baseball could be hit. Three papers detailed the extreme degree of sophistication found in the materials and designs used for the spokes, frames, suspension systems, and rims of bicycles. The symposium ended with a panel discussion by four state-of-the-art manufacturers of bicycle components.

SEND BULLETIN NEWS TO:

$$
\text { Editor, MRS Bulletin }
$$

Materials Research Society

9800 McKnight Road

Pittsburgh, PA 15237-6006

Fax: (412) 367-4373

E-mail:Bulletin@mrs.org 